\title{
Digital Fabrication and its Meaning for Photography and Film
}

\section{Matthew Crippen}

[Presented on 28 October 2016 to the Coimbra Conference On the Virtual, University of Coimbra, Coimbra, Portugal. A revised version was published three years later under the same title as pages 119-131 of Conceiving Virtuality: From Art to Technology, edited by J. Braga (New York, New York: Springer, 2019). 


\title{
Digital Fabrication and its Meanings for Photography and Film
}

\author{
Matthew Crippen
}

\begin{abstract}
Bazin, Cavell and other prominent theorists have asserted that movies are essentially photographic with more recent scholars such as Carroll and Gaut protesting. Today CGI stands as a further counter, in addition to past objections such as editing, animation and blue screen. Also central in debates is whether photography is transparent, that is, whether it allows us to see things in other times and places. I maintain photography is transparent, notwithstanding objections citing digital manipulation. However, taking a cue from Cavell-albeit one poorly outlined in his work - I argue this is not so much because of what photography physically is, but because of what "photography" has come to mean. I similarly argue digital technologies have not significantly altered what cinematic media "are" because they have not fundamentally modified what they mean; and that cinema retains a photographic legacy, even when it abandons photographic technologies to digitally manufacture virtual worlds.
\end{abstract}

Introduction

In the post-WWII era, a number of prominent scholars suggested that film is essentially photographic (e.g., Bazin 1951; Cavell 1979). Since then individuals such as Noël Carroll (1996, 2008), Berys Gaut (2010) and lan Jarvie (1987) have charged it is not, and for reasons not easily challenged. Without disputing this, I aim to highlight the extent to which movies retain a photographic legacy, even in an age when CGI can be used to fabricate virtual worlds. In other words, I hope to show that the photographic legacy continues to define what movies mean to us, even in cases when photographic technologies are left behind. 
Though anticipating some resistance to this thesis, I take for granted that most accept that photography is historically linked to the development of cinema. I therefore presume that a thorough understanding of cinema entails a discussion of photography, and in examining the latter, I defend the transparency thesis. That is, with thinkers such as George Santayana (c. 1900-1907), André Bazin (1951), Stanley Cavell (1979) and Kendal Walton (1984), I argue that photographs allow us to see things in other times and places, notwithstanding objections citing digital manipulation. However, taking a cue from Cavell-and one poorly laid out in his work-I argue this is not so much because of what photography physically is, but because of what "photography" has come to mean. I similarly maintain digital technologies have not radically shifted what cinematic media "are" to us because they have not fundamentally altered our concepts of movies; and this, in part, because filmmakers continue to emulate older, established modes of production in CGI invented worlds, not to mention cartoons, though I attend only briefly to the latter.

I begin by explicating my approach, which considers what photography iswhether digital or photochemical-by examining what it has historically meant to us. While defending the transparency thesis, I dispute some prominently cited bases for it. Specifically, I argue that proponents of the transparency thesis and the related indexical view, which holds photographs are imprints of the world, tend to overemphasize the physical nature of photography and neglect cultural-historical meaning. I also argue that adversaries do the same, and further that it does not make sense to advance claims 
about the ontology of photography-a human, cultural product-apart from historicalcultural interpretations of what it is and what it means. After this, I consider the extent to which meanings of photography enter into our understandings of what cinematic media are. I focus on how digital technologies are pressing conventional concepts of film, yet also how art forms retain historical lineages and therewith established meanings about what they are.

\section{Photography and a Plea for History}

The indexical view of photography, as Pamola Atencia-Linares (2012, p. 19) summarizes without fully endorsing it, holds that photographs "bear a causal relation to their content," much "like shadows and fossils." This means that content "in photographs depends causally, and counterfactually, on the object that was in front of the camera," and also that content "is not essentially dependent on the photographer's intentions." Defenders of this position hold that compared to paintings, which are interpretive, photographs are not products of imagination. Susan Sontag (1973), to give one example, writes that

a photograph is not only an image (as a painting is an image), an interpretation of the real; it is also a trace, something directly stenciled off the real, like a footprint or a death mask. While a painting, even one that meets photographic standards of resemblance, never does more than state an interpretation, a photograph never does less than register an emanation (light waves reflected by objects) - a material vestige of its subject in a way that no painting can be (p. 120). 
Numerous defenders of the indexical view advance comparable ideas, emphasizing physical processes involved in making photographs. Key claims are that the photographic image depends counterfactually on what was in front of the camera and that images are produced through automated mechanical processes and consequently not subject to interpretation.

Building on this kind of outlook, some also argue that photographs are transparent, meaning they are windows allowing us to see into times and spaces removed from our own. Santayana suggests that photography gives us the "unalloyed fact" (c. 1900-1907, p. 397), and Bazin observes that seeing things by means of motion photography is akin to seeing them through "mirrors" (1951, p. 97). Walton (1984), who is most famous for advancing the transparency thesis, offers a comparable analogy, comparing photographs to "telescopes and microscopes [that] extend our visual powers" (p. 255). He adds that with the assistance of photography, we can "see into the past" (p. 251). Cavell (1979) echoes the point, writing that "[t]he reality in a photograph is present to me while I am not present to it; and a world I know, and see, but to which I am nevertheless not present [...], is a world past" (p. 23). That the photographed world "does not exist (now) is its only difference from reality" (p. 24). What is common to these accounts is that they all hold that to see a photograph of, say, an actress is to see the actress herself, as opposed to a mere representation of her. As with advocates of the indexical view, moreover, transparency proponents maintain that photographs register emanations from the world, upon which they counterfactually depend. 
Though sympathetic to such accounts, and while I defend them later, I see a problem with how many are constructed, namely, that explanations focus on how photographs are physically made, less on what "photography" means, which is related but not identical to the material processes. Interestingly and at the same time, some contesting the transparency thesis do the same. Gaut (2010, p. 89), for instance, highlights problems in Walton's account by means of illustrations emphasizing physical, causal relations. Gaut, in one case, describes two clocks, with the hands of clock B radio linked to those of A. This means that B's movements are automatic, mechanical facsimiles of A's. As such, they counterfactually depend on A's, and are not a product of human interpretation. In a second illustration, he talks about an indistinguishable, mechanically produced plaster cast of an artifact. Gaut points out that few would claim that in seeing Clock B, they see A, or in seeing the cast, they see the original, even though this should follow from Walton's account. Although I accept Gaut's criticisms of Walton, I hope to show later that a transparency account emphasizing what photography has historically meant is more robust.

A separate line of attack acknowledges a relation between the transparency thesis and meaning, particularly as influenced by culture, but then questions it on such grounds. For example, Aleksandra Alcaraz (2015), drawing on André Rouillé, suggests the transparency thesis is a questionable belief that emerged as a counter to the "crisis of truth" that surfaced "after the Romantic period" when "doubt in objectivity appeared" (pp. 7-8), with photography seeming to offer one avenue out. The 
observation itself may be correct, and might form a basis for a critique of a culture that attributes greater objectivity to outcomes divorced from human judgment; and it is indeed because photographs are products of automatic mechanical processes that many have given them greater epistemic value than paintings. Statistical analysis is comparable insofar as $p$-values of .05 or .001 are automatically adopted without critical judgment by the scientific community; using other values, even if appropriate to research, is rejected as subjective bias. It cannot be denied, moreover, that erroneous views have arisen for cultural reasons. This happened, for instance, when people clung to geocentric models partly because of religious beliefs that located humans at the center of the universe, although it is worth adding that such models can accord with data (see Crippen, 2010, pp. 484-485, 501, fn. 2). At the same time, however, no comparable mistake has occurred in significant degree with photography, whether photochemical or digital, for experts and most educated laypeople have more or less known how it works all along. Moreover, it does not make sense to advance ontological claims about photography-a human, cultural product-apart from historical-cultural interpretations of what it is.

Evan Cameron (2004) makes this point generally of artifacts. Paraphrasing the philosopher and archeologist R. G. Collingwood, Cameron asks us to suppose that an archaeologist at work upon a site between Tyne and Solway were to uncover yet another elongated section of shaped rock, aligned with others, that might seem to have been part of the wall. What must the archaeologist do to come to understand what has been uncovered? 
The archaeologist must acknowledge that the object is an artefact that was constructed by human beings in the past to serve as a means towards ends they had wished to accomplish. [...]

To learn how an artefact was intended by its makers to mean (to be used), therefore, an archaeologist must engage unexceptionally in the evidentiary and open-ended task of coming to imagine better how its makers had tried to solve the historically specific problem they had faced by making it as they did (2004, pp. 6-7).

This highlights a difference between investigations of human artifacts versus physical nature per se. With the solar system, accounts likely improve as we focus more on physical nature alone and leave culturally based interpretations behind, however unavoidable they may be. With a Roman artifact, however, physical analysis in the absence of cultural-historical explanation yields little. After all, knowledge of what the artifact is entails a sense of how it was used and what it meant to the culture that produced it.

The same holds with photographs, which are artifacts. Consequently those either defending or attacking transparency accounts based on what photography physically is while neglecting cultural significance adopt equally mistaken approaches. So too do those challenging transparency accounts because they are cultural. This is something like noting that a sharp tool intended by a past culture as a writing instrument would have been more effective as a weapon, and then concluding therefore that it is not in fact a writing instrument, but instead a weapon. 


\section{Photography and Meaning}

As early as Santayana and continuing with others such as Bazin, Cavell and Walton, theorists have argued that photography allows us to see things that exist in other time and space. In this section I offer a defense of the position, and in the next consider what it might mean for cinema, especially in light of recent digital advances. However, rather than a protracted discussion, I here provide an abbreviated illustration drawn from an empirical experiment (see Crippen, 2015, 2016). In addition to brevity, the experiment helps show that the question of what photographic media are is a question about their meaning.

The experiment begins with two paintings of Jesus in which he looks different. When asked whom the paintings are of, the response is always "Jesus." Following this first step, people are presented with photographic stills with two different actors playing Jesus and the same question. In this second instance, people hesitate to say the stills are of Jesus, instead stating they are of the performers playing him. This is noteworthy because there is no record of what Jesus actually looked like, which means the performers in the photographs could, in principle, have also modeled for painters.

Cavell's (1979) analysis cast light on why people respond differently to the paintings and photographic stills. In his own example, he argues that upon encountering a building in a painting, we do not take its existence for granted, recognizing it may be a product of imagination. If we conclude it exists, it is typically because of external information, as when recognizing it as a well-known site such as the White House. In 
Cavell's words, it accordingly "only accidentally makes sense" to ask "what lies behind it, totally obscured by it" (p. 23). However, the same question has historically been appropriate in the case of photographs because people have historically understood "photography" to mean something showing things that exist or once did.

Testifying to this is the fact that many objected that something unphotographic was misleadingly presented as photographic when the Giza pyramids were repositioned to better fit a 1982 National Geographic cover. In the words of an editor in chief from the same publication, a "firestorm" resulted (Goldberg, 2016, n.p.), and similar reactions have occurred more recently when digitally doctored images have been presented as photographs (see Cooper, 2007; Safi, 2016). This indicates that upon encountering what we understand to be a photograph, as opposed to a photorealistic painting or CGI image, people have overwhelmingly taken for granted that the building or whatnot in it exists or once did and that the image has not been manipulated post hoc. Upon learning that an image is doctored, people have, at least in the past, questioned the legitimacy of calling it a "photograph." Paintings have a different meaning, and are not taken as truth claims about what they portray, and this helps explain why people unhesitatingly identify Jesus in the paintings: they at least tacitly recognize the images might be products of imagination. So even if models were used, the paintings are principally of Jesus and of models accidentally, and we only feel confident models were used through information not in the painting, for instance, comments in an artist's journal. By contrast, the models are internally and perhaps analytically related to photographs in 
that we understand that things called "photographs," by definition, show things that exist or once did. ${ }^{1}$

Notice also that the fact that photographers use different film stocks, focal lengths, lighting and so forth-all standard objections to the transparency thesis (see, for example, Carroll, 1996, pp. 47, 57-58)-does not alter this meaning. That is, regardless of these variations-unless perhaps so extreme as to destroy recognizability-people consistently behave as if photographs of friends and family are a means by which we see them. This makes sense because the aforesaid variations could be introduced if we peered at the performers through a telescope, darkened pitted glass, in sunshine versus incandescent light, and in such cases few would claim they are not seeing them. Lack of retinal disparity and motion parallax are not objections either since both would drop out if we gazed at models while motionless with one eye close, and once again few would deny we are seeing them. One feature that has, however, historically made people question the legitimacy of using the term "photograph" is post hoc manipulation such that images are not produced through automatic mechanisms. This highlights that the physical processes by which photographs are made relate to what we understand photography to mean. However, examining the physical nature of photography alone will not tell us much about its meanings, nor what it is to us. Gaut's earlier cited examples in fact indicate that physical

\footnotetext{
${ }^{1}$ Some of the explanation here given paraphrases and elaborates on that offered in Crippen 2015, pp. 84-85; 2016, p. 170.
} 
parameters alone do not dictate how we encounter things, for people do talk as if they see loved ones by means of photographs; and the experience of seeing through time is palpable for those who have discovered, for instance, precious $8 \mathrm{~mm}$ home-movies of grandparents from decades past. However, it is unlikely people would experience radiolinked clocks or indistinguishable plaster imprints of artifacts in comparable ways.

How much does digital photography change this? Against what some maintain, I argue very little. Thus, for example, Alcaraz (2015) writes that although "analog and digital images seem ... very similar or even the same, when perceiving a digital image we can never be sure that it is true" (p. 1). She adds: "We can no longer believe in the truthfulness of digital images, since we can never be sure to what extent they represent the world around us[...], or whether they might be simulacra" (p. 11). The claim itself is of course true, but it was also true before the advent of digital photography, with doctored images around almost as long as photography has existed. The National Geographic cover is one example. A variety of others abound. Early on pointillist and impressionist images were rendered with photographic technologies. Advertisers airbrushed makeup models before the advent of photoshoping. Moreover, AtenciaLinares (2012) observes a protracted history of blending photographs to create the impression of entities that do not exactly exist, as when Wanda Wultz mixed a feline face with hers. Atencia-Linares also discusses artists creating images by passing light over film emulsions, in effect drawing with light, and adds that this "is indeed a photographic process" (p. 22). However, this is arguably a misuse of words, and the 
process is more accurately characterized as "photochemical" because almost nobody will perceive the result as a photograph, just as many will question whether they are really encountering a photograph if they see a human-feline face, or behold an image, then learn portions were digitally altered in significant ways, superimposed or removed. In short and to repeat, calling something a "photograph" has historically meant making a tacit truth claim about objects seen by means of it, namely, that they exist or once did. When this is drawn into doubt, so too is the legitimacy of using the word "photograph." Having said this, digital technologies have added new means of trickery, even if trickery itself is nothing new. Barbara Savedoff (2008), in a balanced assessment, writes: "In a world where digital manipulation-digital collage-has become the norm, we may simply come to assume that a photograph has been altered if it is at all challenging to read it as straight" (p. 137; see also Benovsky, 2014, p. 722). However, while the threshold that challenges is increasingly lower, digital cameras are predominately employed as their photochemical predecessors were: to capture the world. Hence we still take digital recordings of misdeeds as evidence, whereas paintings have never been accepted. In legal proceedings, perhaps, we would wish to verify digital photographs, but this would also be the case with photochemical images if doubts about authenticity existed. That digital photographs are taken as evidence also explains the surge of selfies with celebrities or at famous sites.

To understand something as "photographic" is still to tacitly accept a truth claim about what it shows, which is why, for instance, Reuters fired a top photo-editor and 
removed Adnan Hajj's photographs from its site after some were found to be digitally manipulated (see Cooper, 2007). Digital media have, to be sure, made it easier to manipulate results post hoc. For example, people might easily brighten eye color in selfies, but this is only a more ubiquitous variation of what has occurred all along, as in airbrushed glamor shots. For this reason, the meaning of "photography" is perhaps changing and may depart widely from currently established meanings in the future. However, so far it has not changed in significant degree-hence the uproar over Hajj's images or the more recent banning of climbers from Nepal for producing doctored images of an ascent of Mount Everest (see Safi, 2016), something that would not have happened had a painter rendered a portrait of them at the summit. The possibility of manufacturing photographic-looking products was always there; digital technologies just make it more effortless.

\section{Movies and Meaning}

Casablanca (1942), excepting a few animated sequences with maps and the like, is a film produced by means of motion photography; and according to the conception of photography advanced through the Jesus example, this implies that when we see Ingrid Bergman and Humphrey Bogart through the screen while viewing the film, we see performers who once lived, wearing garments that actually existed, doing things they did on past movie sets. When Bergman smiles, when Bogart lights a cigarette, we witness events that really occurred. Thus while engaging us with a fictional story, the 
movie also confronts us with a world that is anything but fictional-a world we can see without it being present in our space. In this regard, at least, Casablanca is within the domain of motion photography, and to that extent, arguably transparent. However, many films are obvious counterexamples. In spite of this, I still want to argue that photography remains connected to what film means, indeed, even in cases when photographic technologies are largely abandoned.

Perhaps the most obvious counterexample is cartoon animation. When we screen scenes from “The Sorcerer's Apprentice" in Disney's Fantasia (1940) we do not see anything that ever existed before the camera. Cavell says the projected world is a world of the past, a world that does not exist now, and that apart from this, "[t]here is no feature, or set of features, in which it differs" $(1979$, p. 24). Yet reacting to the first edition of The World Viewed, Alexander Sesonske (1974) responds that every feature differs in the case of cartoons: "Neither the space nor the laws of nature are the same" (p. 564). The events in "The Sorcerer's Apprentice" do not closely approximate anything we would see in the world, and "there is no past time at which these events either did occur or purport to have occurred" (Sesonske, 1974, p. 564). Cartoon animation raises a clear objection to those either applying the transparency thesis to film or arguing movies are photographic, as Bazin and Cavell claim. Animation also raises questions about the purported importance of realism in cinema-by which I just mean that things look real, even if stories are preposterous, as in many superhero and sci-fi flicks. Animated cartoons obviously do not manifest this kind of realism, but nonetheless 
captivate. Few laugh when Bambi's mother gets shot. Moreover, films departing even further from both realism and photographic technologies can be made. One could, for instance, use the scratch techniques of Len Lye to render abstract images onto celluloid by hand, and then forgo the step of photographically mass-producing the finished result. While this perhaps would not count as "a movie," regarding it as an instance of "film" or "cinema" is perfectly intelligible.

In addition to all this, there are many "middle-cases" that challenge the notion that film is either photographic or transparent. When we see dinosaurs in Jurassic Park (1993) or gigantic creatures in Avatar (2009), we see a range of entities that never existed in front of the camera. The images may be partly photographic, as when human performers flee digitally constructed beasts. Hence the end product is not the unadulterated result of photographic automatism. So Gaut (2010), among others, is right when he says in reference to CGI that "cinematic art now deploys a possibility that painting already possesses, since it does not require some independently existing object in order to create expressive content" (p. 50). But while technically correct, this is nothing new to cinema. Over a century ago, audiences saw colored bursts of handtinted gunfire in shootouts in The Great Robbery (1903). A culminating scene from Anchors Aweigh (1945) pairs Gene Kelly with Jerry the mouse, blending live action with cartoon animation, and Zelig (1983) combines elements from different photographic worlds, inserting Woody Allen into old footage with Adolph Hitler. In the original Star Wars movies (1977, 1980, 1983), Harrison Ford retreats from weapons fire he never 
actually encountered. Forest Gump (1994) goes further, albeit this time with the aid of digital technologies: not only is Tom Hanks' image introduced into archival footage with John F. Kennedy, but the brightness of the pixels around Kennedy's mouth are manipulated, making movements better match lines provided by screenwriters.

Gaut (2010) adds that "traditional film is ontologically realistic," insofar as it is of things that were and events that actually happened, "but digital film is not in all cases" (p. 68). Only traditional film is not always ontologically real, as most of the above examples illustrate. In uncounted movies and for a long time, we have seen things that did not exactly happen, and not merely as a result of special effects, but also through montage or editing. Suppose, to borrow from Vsevolod Pudovkin (1926), that a man is filmed,

...falling from a [fifth-story] window into a net, in such a way that the net is not visible on the screen; then the same man is shot falling from a slight height to the ground. Joined together, the two shots give in projection the desired impression [of a man falling from an appalling height] (p. 85).

In the individual shots we here see events that actually happened, but not in the combination of the two. The man did not plummet five stories. "The catastrophic event $\ldots$ is the resultant of two pieces of celluloid joined together" (p. 85).

So a few things to note: in the digital era, film is often not fully photographic and consequently not properly transparent, yet it almost never has been in its century plus history. The question I want to address is the extent to which the advent of digital filmmaking and especially CGI has changed what movies are to us; and while the claim 
that film is essentially photographic is untenable, the position, especially as developed by Cavell, highlights an important point: that ontological questions about film relate to or are the same as questions about what film means to us. Cavell suggests just this in the first pages of the World Viewed when he explains that he came to see that "the answer to the question 'What is the importance of art?' is grammatically related to, or is a way of answering, the question 'What is art?'" Import relates to significance and meaning, and questions about something's important are historical quandaries. History of course changes, and meanings evolve. Once film was something you "shot." The earliest films were, in fact, composed of a single shot. Later, shots were strung together, but largely as a matter of convenience-due to a scene change or because the scene's length exceeded that of the reel and so on. It was not long, however, before editing became an aesthetic device. It was used to create continuity (and in some later cases, discontinuity), to structure scenes, to moderate mood and tempo and as a means of constructing events not actually recorded on film; it became an expository device (e.g. establishing shots), a narrative device, a way of building suspense and tension and a way of conveying simultaneously occurring events, as when cutting between fleeing outlaws and a pursuing posse. Editing changed how films were made and how cinema functioned as an expressive medium. Films, Pudovkin (1926) would say, are "not shot but built, built up from the separate strips of celluloid that are raw material" (p. 24). "The foundation of film art is editing" (p. 23). "Every object must, by editing, be brought upon the screen so that it shall have not photographic, but 
cinematographic essence" (p. 25). Whether editing makes for cinematographic essence is a matter of debate, and one that Pudovkin is likely to lose today, but his basic observation that editing changed how films are made and how they communicated to audiences, that is, his assertion that editing shaped what films and filmmaking have historically become and therefore what we understand film to mean, is a claim not easily disputed.

Editing is one tendency that remains constant throughout most of the history of filmmaking. Another longstanding constant-albeit less so-is that makers have tried to create the appearance of reality, cartoons and abstract films being exceptions. This has sometimes involved counterfeiting reality, but notice it is the appearance of reality that has been counterfeited. In superhero movies and sci-fi fantasies, for example, the overwhelming aim is to make preposterous and fictional events appear as they might if they actually happened. "Explicit artifice is," as Cavell observes, "quite rare; not just rare, but specialized" (1979, p. 196), as in the case of the partly animated dream sequence in Vertigo (1958), where the departure from photographic realism is intentionally obvious. Most of the time such departures are avoided, and when filmmakers employ artifice, they do so with the hope of making it invisible. If an airplane flies across the screen, and it is obvious that it has been digitally inserted, then the special effects department has likely not succeeded in its job. The conspicuousness of artifice is here its failure. 
It is clear, then, that pre-digital and digital filmmakers have both overwhelmingly endeavoured to create the appearance of reality, whether everyday or fantastical. Sometimes doing so involves counterfeiting it, as in cases just discussed, but also in more recent instances such as Rogue One (2016) where CGI is used to a significant extent. At the same time, cameras remain prevalent in this movie and others precisely because creating the appearance of reality with them is less labour intensive, more cost effective and usually just more convincing. Furthermore, motion photography has an influence even in cases when not used. It is felt distinctly, for example, in cartoons since animators import editing techniques from motion photographic filmmaking. A lesson here is that art forms do not abandon historical legacies even when relinquishing old modes of production.

The photographic legacy indeed remains in digitally constructed virtual worlds. As John Mullarkey (2009) notes: "lens flare-an artefact of 'conventional' filmmaking that was once avoided but eventually became a stylistic cliché of the 1960s and 1970s -is these days reproduced artificially" in computer-generated productions (p. 54). This, he goes on to explain,

...is one attempt to emulate the imperfections of the optical in order to be real-its flaring, its blurriness. Indeed, the optical and analogical are inherently limited (one can only move so fast, one can only go so high in a crane shot), and the shortfall from perfection, no matter how curtailed by effort, is also the index of material power. It is the weightlessness of CGIthe ability to see anywhere in focus and move anywhere at speed-that fails to convince us because it offers no material resistance, no material freedom (p. 195). 
Gaut (2010) elaborates on the same point:

What is striking about the notion of photorealism is that it does not employ a comparison of the image to how a real object would look to provide a standard of realism [...], but rather compares the image to a photograph of an object. This notion of realism is, then, a derivative one. The use of the photograph as the standard is illustrated by the introduction by digital animators of such things as film grain, motion blur ... and lens flare into digital images. These are not things that accompany our normal seeing of an object, but are artefacts of photography. Often the standard of photorealism is set by the traditional photograph, rather than the digital one. For instance, film grain is a feature of traditional film, because of the silver salt deposits used, but does not occur in digital photographs [...]. Other features employed in digital animation are common to traditional and digital photography: motion blur occurs because the exposure time of a shot is sufficiently lengthy that the object has discernibly moved during it; and lens flare happens when some light from a light source bounces away from the lens, instead of going through it. In the case of digital animation, there is no film grain, no motion blur (the represented objects are constructs, rather than independently existing), and no lens flare, since the lens is a "virtual" one, being merely a point of view onto the constructed digital world (pp. 66-67).

This is to say, graininess, blur, lens flare and the like make the experience of watching CGI films even more removed from what we would see if we witnessed events in person since such phenomena would be absent. They are nonetheless added, to re-quote Mullarkey, in an "attempt to emulate the imperfections of the optical in order to be real." That is, they are added because they are a part of photochemical filmmaking and photography, which has ubiquitously been taken to have privileged access to reality. At this point in time, moving images accordingly seem less real without these imperfections, and this because of the earlier history of photochemical filmmaking. 
This illustrates, once again, how the photographic legacy remains in film even when it abandons photographic technologies. It suggests, in other words, that photography is not easily subtracted from what films mean to us and how they are made-in short, what they are. Discussions about the making of Avatar (2009) illustrate the point in detail. The moviemakers digitally manufactured lens flare and blurriness; they limited depth of field and added the appearance of overexposure-all unnecessary in CGI. The production team, moreover, endeavoured to make the director and audience feel as if conventional cameras were employed. Joe Letteri, a visual effects supervisor, explained in a 2010 documentary that a system was set up to allow the director to behave as if on "a live action stage." Rob Legato, a virtual cinematography consultant, added: "And the camera can do anything. It can be a crane, it can be a steady-cam, it can be all just purely handheld. ... It's basically as close to live action as one can get in a CG invented world." Notice that while the virtual camera can "do anything," the makers of Avatar mostly imitated constraints of conventional cameras, and fabricated optical imperfections linked with them. In terms of performance capture, they limited themselves similarly, with director James Cameron remarking in a 2010 interview that they took a human performance "with no diminishment whatsoever, and then added to it," for example, by introducing features of fictitious alien species. So when asked "what percentage of the actor's performance came through in the final character, [he] say[s] 110\%." 
Recently digital technologies have been used in even more extraordinary manners. Facial performance capture, in combination with a body double, was employed to create a young version of Arnold Schwarzenegger in Terminator Genisys (2015). Similar techniques were used to resurrect Peter Cushing from the dead to play his 1977 character Moff Tarkin in Rogue One. At the same time, barring circumstances like these and that of Avatar, conventional cameras and recording devices remain an easier and more effective method of creating the appearance of reality than digitally constructing minute ripples of muscle and subtleties of line, shadow, tone and countless other alterations undulating in the human face. This is evidenced by the fact that filmmakers avoid such techniques most of the time because using them is laborious, expensive and often not that convincing. Moreover, Schwarzenegger and Cushing's faces were impassive because of their roles and thus easier than usual to construct, and performance capture was still used, meaning actors were essential.

Many filmmakers currently bypass the camera when, due to costs or feasibility, they are unable to produce some kind of event in front of the camera in a way that looks photo-real, and notice that the makers of Rogue One used old footage-not CGIfrom the movie made 30 years earlier when out-takes were available for some of the fighter pilots. Though one might debate the credibility of many computer-generated effects and movies that rely heavily on them, it seems that a desire for the visual appearance of reality is often the very thing that drives filmmakers away from the camera. It is also a large part of what keeps them attached to it: the camera is still the 
most reliable and generally effective means of producing the appearance of reality, and this may not change for some time to come. Cameras with optical lenses-and not CGI-remain overwhelmingly ubiquitous even after the introduction of digital technologies. Filmmakers, in short, still largely aim to achieve the same results as they did before digital technologies became common; and though images are typically recorded digitally these days due to cost, ease of editing, manipulability and more, cameras with optical lenses are still the primary way that performances and events are captured, and even when they are digitally constructed, the overwhelming aim is to make them appear photographic. For such reasons, digital technologies have not radically altered what movies "are" to us, or more accurately, what they mean.

Meanings are not, to be sure, disconnected from technologies, so that filmmaking and photography would not mean what they do if not for the automated mechanical processes and unprecedented ease with which images can be made to show the world. However, meanings are not solely determined by technologies, much less by philosophers. Far too many philosophers neglect this last point, including even Wittgenstein, whose supposed examples of everyday language were not everyday but schematized and one might say, essentialized (see Cameron, 2004). Realism, a standard established in cinema because of its development out of photographic technologies, remains a mainstay. It is what people often expect and a part of what movies mean to them, even to the point that imperfections in old ways of doing things are intentionally introduced to digitally constructed images. Filmmakers continue to rely on optical 
cameras, and even when digitally producing fabricated, virtual worlds, cinema retains a legacy from photographic traditions.

\section{References}

Alcaraz, Aleksandra Łukaszewicz. 2015. Epistemic function and ontology of analog and digital images. Contemporary Aesthetics 13: 1-14.

Atencia-Linares, Paloma. 2012. Fiction, nonfiction, and deceptive photographic representation. Journal of Aesthetics and Art Criticism 70: 19-30.

Bazin, André. 1951/1967 What is Cinema?, trans. Hugh Gray, 95-124. Berkeley: UC Press, 1967.

Benovsky, Jiri. 2014. The limits of photography. International Journal of Philosophical Studies 22: 716-733.

Cameron, Evan. 2004. From Plato to Socrates: Wittgenstein's journey on Collingwood's map. AE: Canadian Aesthetics Journal 10: 1-30.

Carroll, Noël. 1996. Theorizing the Moving Image. Cambridge: Cambridge University Press, 1996.

Carroll, Noël. 2008. The Philosophy of Motion Pictures. Oxford: Blackwell Publishing, 2008

Cavell, Stanley. 1979. The World Viewed, enlarged edition. Cambridge: Harvard University Press. 
Digital Fabrication and its Meanings for Photography and Film

Cooper, Stephen D. 2007. A concise history of the fauxtography blogstorm in the 2006 Lebanon War. The American Communication Journal 9: 1-34.

Crippen, Matthew. 2010. William James on belief: Turning Darwinism against empiricistic skepticism. Transactions of the Charles S. Peirce Society 46: 477-502.

Crippen, Matthew. 2015. Pictures, experiential learning and phenomenology. In Visual Learning, vol. 5: Saying by Showing, Showing by Saying - Pictures, Parables, Paradoxes, ed. András Benedek and Kristof Nyiri, 83-90. Frankfurt am Main: Peter Lang Publishers.

Crippen, Matthew. 2016. Screen performers playing themselves. British Journal of Aesthetics 56: 163-177.

Gaut, Berys. 2010. A Philosophy of Cinematic Art. Cambridge: Cambridge University Press, 2010.

Goldberg, Susan, Editor in Chief. 2016. How we check what you see. National Geographic 230, n.p. [editorial precedes pagination].

Jarvie, Ian. 1987. Philosophy of the Film: Epistemology, Ontology, Aesthetics. London: Routledge.

John Mullarkey. 2009. Philosophy and the Moving Image: Refractions of Reality. London: Palgrave Macmillan.

Pudovkin, Vsevolod. 1926/1970. Film Technique. In Film Technique and Film Acting, ed. and trans. Ivor Montagu, 19-220. New York: Grove Press. 
Digital Fabrication and its Meanings for Photography and Film

Safi, Michael. 2016. Indian couple banned from climbing after faking ascent of Everest. The Guardian, 30 August.

Santayana, George. c. 1900-1907/1967. The Photograph and the Mental Image, In Animal Faith and Spiritual Life: Previously Unpublished and Uncollected Writings of George Santayana with Critical Essays on his Thought, ed. John Lachs, 391-402. New York: Appleton-Century-Crofts.

Savedoff, Barbara. 2008. Documentary Authority and the Art of Photography. In Photography and Philosophy: Essays on the Pencil of Nature, ed. Scott Walden, 111-137. Malden: Blackwell.

Sontag, Susan (1973/2005). On Photography. Rosetta Books LLC.

Walton, Kendal L. 1984. Transparent pictures: Critical Inquiry 11: 246-247. 